الخصائص السيكومتزية لمقياس التنافر المعرفي لدى معلمي المرحلة الابتدائية

|atal

/ / ماجدة محمد على أحمد

\author{
باحثة دكتور اه \\ كلية التربية بقنا - جامعة جنوب الو ادئ
}




\title{
الخصائص السيكومترية لمقياس التنافر المعرفي لدى معلمي المرحلة الابتدائية اعداد
}

\section{/ ماجدة محمل على أحمل}

\author{
باحثة دكتور اه \\ كلية التربية بقنا - بامعة جنوب دكورة الو ادي
}

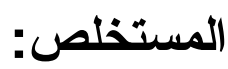

هدف المقال الحالي إلى دراسة الخصائص السيكومنرية لمقياس التنافر المعرفي لدى معلمي المرحلة الابثدائية، وللتحقق من ذلك، نم نطبيق المقياس على عينة قوامها . . . التحليل العاملي الاستكثافي الذى اسفر عن استخر اج خمسة عوامل هم (بُعد العمل، البُعد الاجثماعي ،بُعد التكيف الثخصي ، البُعد العاطفي ، بُعد النطوير والاستمرارية)، وتم التحقق دن نتائج التحليل العاملي الاستكشافي من خلال إجراء التحليل العاملي التوكيدي على بيانات عينة استطلاعية قو امها ـ. . م معلمًا من معلمي المرحلة الابتدائية، وأظهر نتائج التحليل أن مؤشرات المطابقة حققت مطابقة جيدة لمقياس التتافر المعرفي القائم على منتج التحليل العاملي الاسنكثنافي،وللتأكد من ثبات المقباس نم حساب معامل الفا كرونباخوثز اوحت قيم معاملات الفا لأبعاد المقباس ما

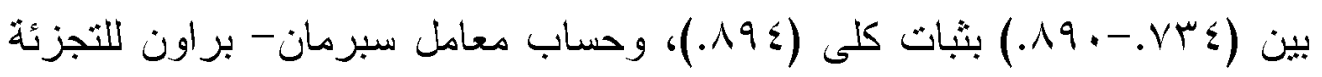

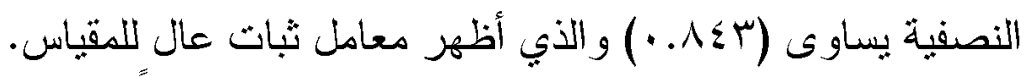
الكثمات المفتاحية: التتافر المعرفي، نتائج المقياس. 
الخصائص السيكومترية لمقياس التنافر المعرفي لاى معلمي المرحلة الابتدائية

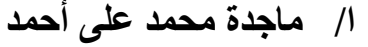

\title{
The psychometric properties of cognitive dissonancescale among the teachers of the primary stage
}

\author{
Magda Mohamed Ali Ahmed \\ $\mathrm{PhD}$ Scholar at Department of Education Principles \\ Qena Faculty of Education, South Valley University
}

\section{Abstract:}

The aim of the present article to study the psychometric properties of cognitive dissonancescale among the teachers of the primary stage,to verify this the scale was applied to a survey sample of 200 teachers of the primary stage, the validity of the scale was confirmed through the exploratory factor analysis that resulted in the extraction of five factorsthey(the work dimension, personal adjustment dimension, social dimension, emotional dimension, development and continuity dimension) theexploratory factor analysis results was verified by Procedure confirmatory factor analysis to a sample of 200 teachers of the primary stage, the analysis showed that fit index achieved a good fit for the cognitive dissonance scale based on the exploratory factor analysis product,to ensure the the reliability of the scale it was account Cronbach's Alphathe values of the Alpha coefficients for the scale dimensions ranged between (.734- .890.), with total reliability (.894), and account the Spearman-Brown coefficient for the split-half equal to (.843), it showed a high reliability coefficient for the scale.

Keywords: Cognitive dissonance, The results of the scale

العدد الر ابع والأربعون




\section{مقدمة - 20 - مقة}

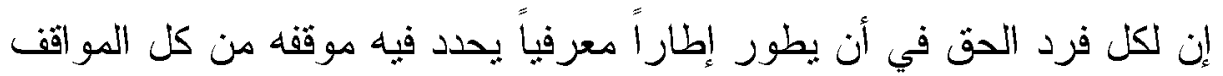
والآراء والمعتقدات والاتجاهات، وكلما زادت ثنافة الفرد ونعليمه كلما زادت لدايه

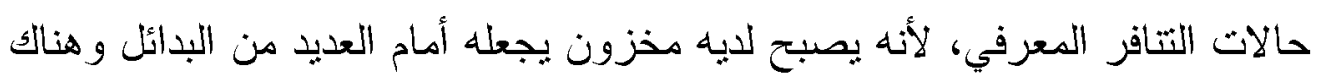

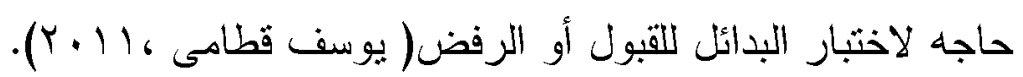

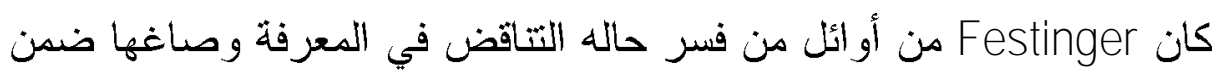
نظرية اسماها نظرية "التتافر المعرفي" وتعتبر نظرية التنافر المعرفي واحدة من أكثر النظريات المؤثرة في علم النفس الاجنماعي، حيث أنها أحدثت ثثرة في التفكير في العمليات النفسية (2018, Kaaronen). وتستند نظرية التنافر المعرفي عند Festinger(1957) على افتراضات أسساسية:-

ا-بميل الثخص الذى يواجه التتافر إلى حالة عدم ارتباح من الناحبة النفسية

ثلاك الحالة سوف تحفز الفرد على محاولة الحد من التتافر ونحقيق التو افق. r-عند وجود الثتافر والدحاولة للدد منه سينجنب الثخص المو اقف والحالات

الني من المحنمل أن نزيد النتافر.

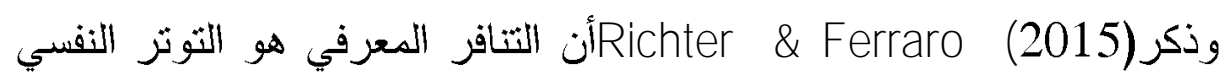

الذب يحدث عندما يكون هناك معنقدين منعارضين في وقت واحد، وعندما ينثأ هذا

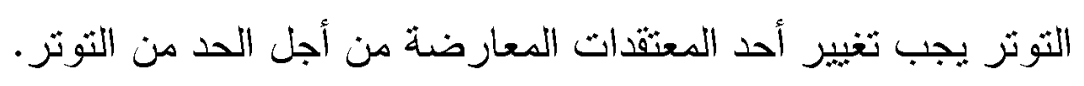
وعرن Festinger (1957) التنافر المعرفي بأن الفرد يعانى من التوتر النفسي

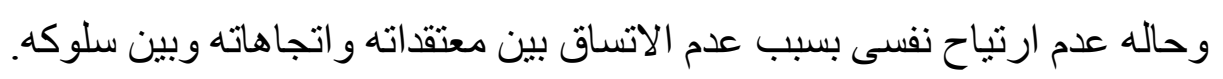
التعريف الإجر ائي للتنافر المعرفي الإني

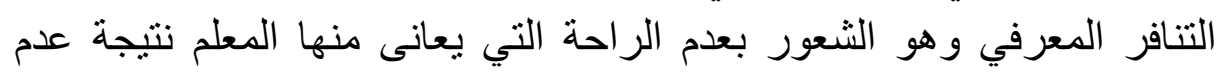

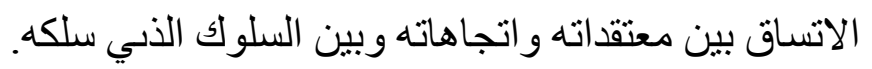




\section{خطوات إعداد المقياس}

\section{1-هدف المقياس}

الهذف من بناء المقباس الحالي هو قياس التنافر المعرفي لــدى معلمـي المرحلــة الابثدائية حيث ثم تصميم المقياس في ضو ه تحليل الدراســات و البـــر امج الأجنبيـــة و العربية الني نتاولت النتافر المعرفي ممايساعد المعلمين في تقييم أنفسهم.

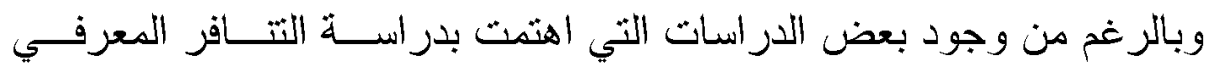
وتتاولته بالبحث والدر اسة إلا انه يوجد قلة في الدراسات العربية التي نتاولت التتافر المعرفي- في حدود علم الباحثة- لدى فئة المعلمين، لذلك دعت الحاجه إلى ثصميم مقياس للتنافر المعرفي لمعلمي المرحلة الابتدائية.

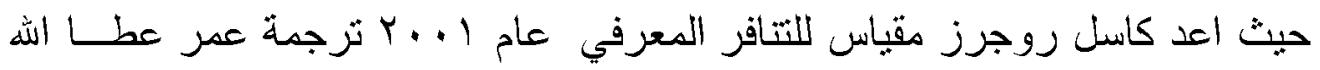

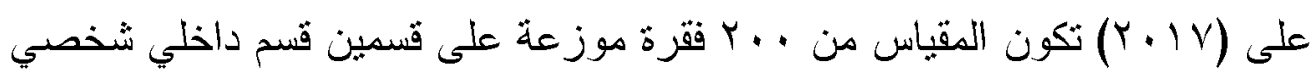
وقسم خارجي غير شخصي ويحتوى كل منها على أربعة أبعاد ويحنوى كل بعد على بلى مب فقرة، وأعدت رنا رفعت شوكت (T ا ـ Y) مقياس لدى طلبة كلية التربية الأساسية الجامعة المستتصرية تكون المقياس من عـ فقرة. r - بكتابة مفردات المقياس أ-اعثدت الباحثنة على نظرية التتافر المعرفي لـ Festinger (1957) في بناء

المقياس. ب-ثم الرجوع إلى العديد من المراجع والمصادر لهذه النظرية، والاطلاع على

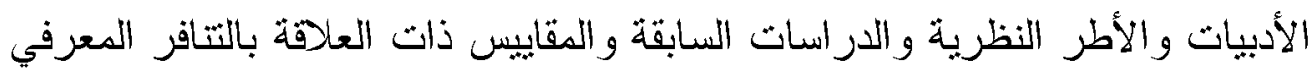
Harmon-Jones \& Harmon-Jones ),Brehm (2007),Burns (2006) - لـ (2007Mckimmie (2015), 
ج-وبناء على ذلك وانساقًا مع الإطار النظري الأى نم الاعثماد عليه في دراسة هذا المتغير وبالاستعانة بالأدبياث و الدراسات السابقة قامت الباحثة بصياغة (^^) عبارة.

د-ثم عرض المقياس في صورثه الأولية على مجموعة من المحكمين بلغ عددهم خمسة محكمين من كليات الثربيةكما هو موضح بجدول (1) وذللك للحكم على مدى ملائمة المفردات ومدى سلامة الصياغة اللغوية وبناء على آراء المحكمين نم تعديل بعض المفردات كما هو موضتح بجدول (Y).

جدول (1) قائمة بأسماء السادة المحكمين

\begin{tabular}{|c|c|c|c|}
\hline جهة العمل & الارجة العلمية و التخصص & 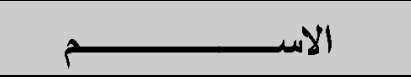 & 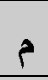 \\
\hline كلية التربية - جامعة & ؤستاذ علم النفس التزبوي & محسوب عبدالقادر الضوى & 1 \\
\hline كلية التربية - جامعة & 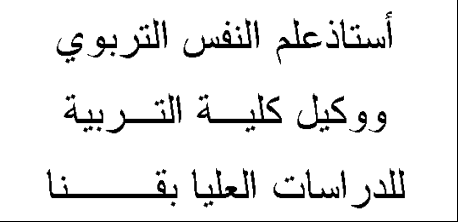 & عصام على الطيب & r \\
\hline كلية التربية - جامعة & أستاذ المناهج وطرق التدريس & بدرية حسن على & $r$ \\
\hline كلية التربية - جامعة & أستاذ مساعد بقسم علم النفس & محمد سيد محمد & $\varepsilon$ \\
\hline للتربية - جامعة القاهرة استات العليا & مدرس علم النفس التربوي & عاصم عبدالمجيد كامل & $\bullet$ \\
\hline
\end{tabular}

"الأسماء مرتبة حسب الدرجة العلمية

العدد الرابع والأربعون


يوضح المفردات التم تعديلها بناء على أراء المحكمين

\begin{tabular}{|c|c|c|}
\hline المفردات بعد التعديل & المفردات قيل التعديل & 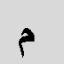 \\
\hline ، وأكنب أثنعر بأنني أمنلك خصائص شخصية في ثيزة & 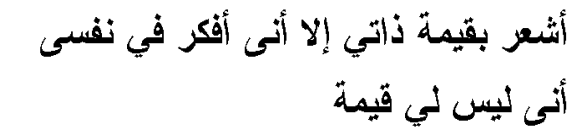 & 1 \\
\hline لكهب أشب التعامل مع تلاميذ المرحلة الابتدائية & أحب التعامل مع الأطفال لكنى أثبر & $r$ \\
\hline نفسى أنى غيائي يزوني شخص كفه كف كنى أرى & 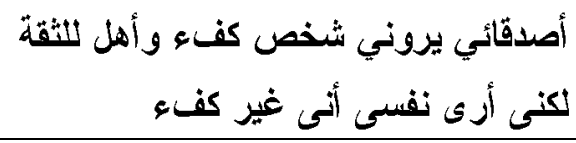 & $r$ \\
\hline ألثرتز من ضجيج التلاميذ لكنى لا أحب & أتوتز من الضوضاء لكنى لا أحب الهدوء & $\varepsilon$ \\
\hline أثثبر أن التطوير تطبيق خطة التنمية المهنية لكن & 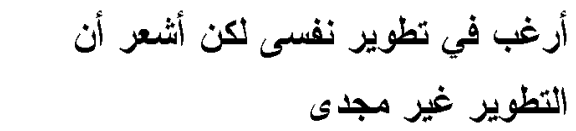 & $\bullet$ \\
\hline
\end{tabular}

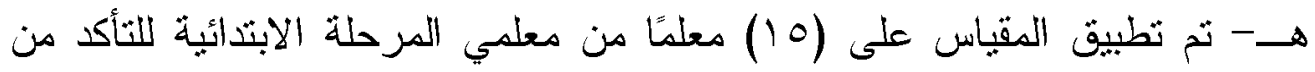

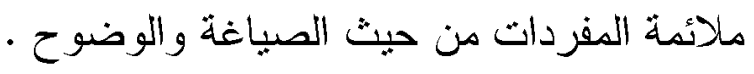

صدق وثبات المقياس

أولاً: صدق المقياس.

-الصدق العاملي validityFactorial

\section{1- التحليل العاملي الاستكثافي Exploratory Factor Analysis}

تم التحقق من شروط التحليل العامليالاستكثافي من خلال :

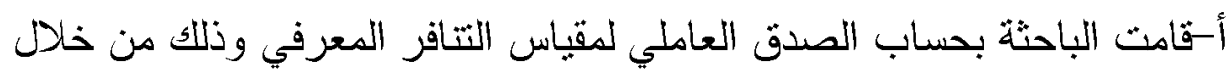
تطبيقه على عينة اسنطلاعبية بلغ عددهم ( (Y) معلمًا مـن معلمـي المرحلـة

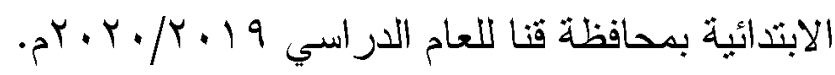




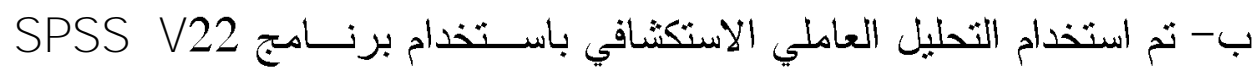

وتم استخلاص العوامل بطريقة المكونات الأساسية Principal Components ، وأنثار أمحمد بوزيان تبغزة (11) أن حجم العينة يعتبر مناسبًا إذا كانــت قيمة اختبار Kaiser- Meyer- Olkin أكبر من (•...)، و بلغت قيمته في البحث

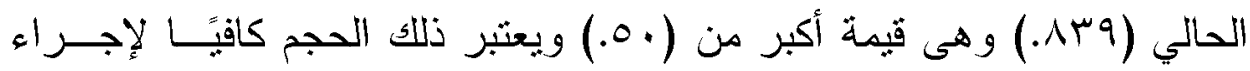

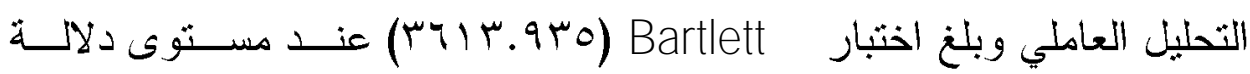
(1 ( . . . ) كما هو موضتح بجدول (r)، وكانت القيمة المطلقة لمحدد مصـفوفة الازتباط Determinant حيث بلغت Determinant = $9.840 E$ - 9 وهى أكبر من (1 ( . . . . ) مما بدل على أن المصفوفة نمثل مصفوفة كاملة.

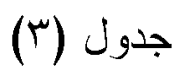

KMO and Bartlett's Test

Kaiser-Meyer-Olkin Measure of Sampling Adequacy.

Bartlett's Test of Sphericity Approx. ChiSquare

df

Sig.

ج- وتم اخذ العوامل التي جذورها الكامنة أكبر أو تساوى الواحد الصحيح. 
د- ونم الاستعانة بطريقة منحنى المنحدرScree polt ويوضح الرسم البياني معيار الإبقاء على العوامل التي يزيد جذورها الكامن عن واحد صحيح، وقد تم استخراج خمسة عوامل استوعبت بس مفردة من المفردات ليصبح قيمة الثباين الكلى له

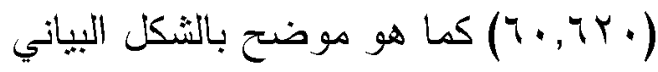

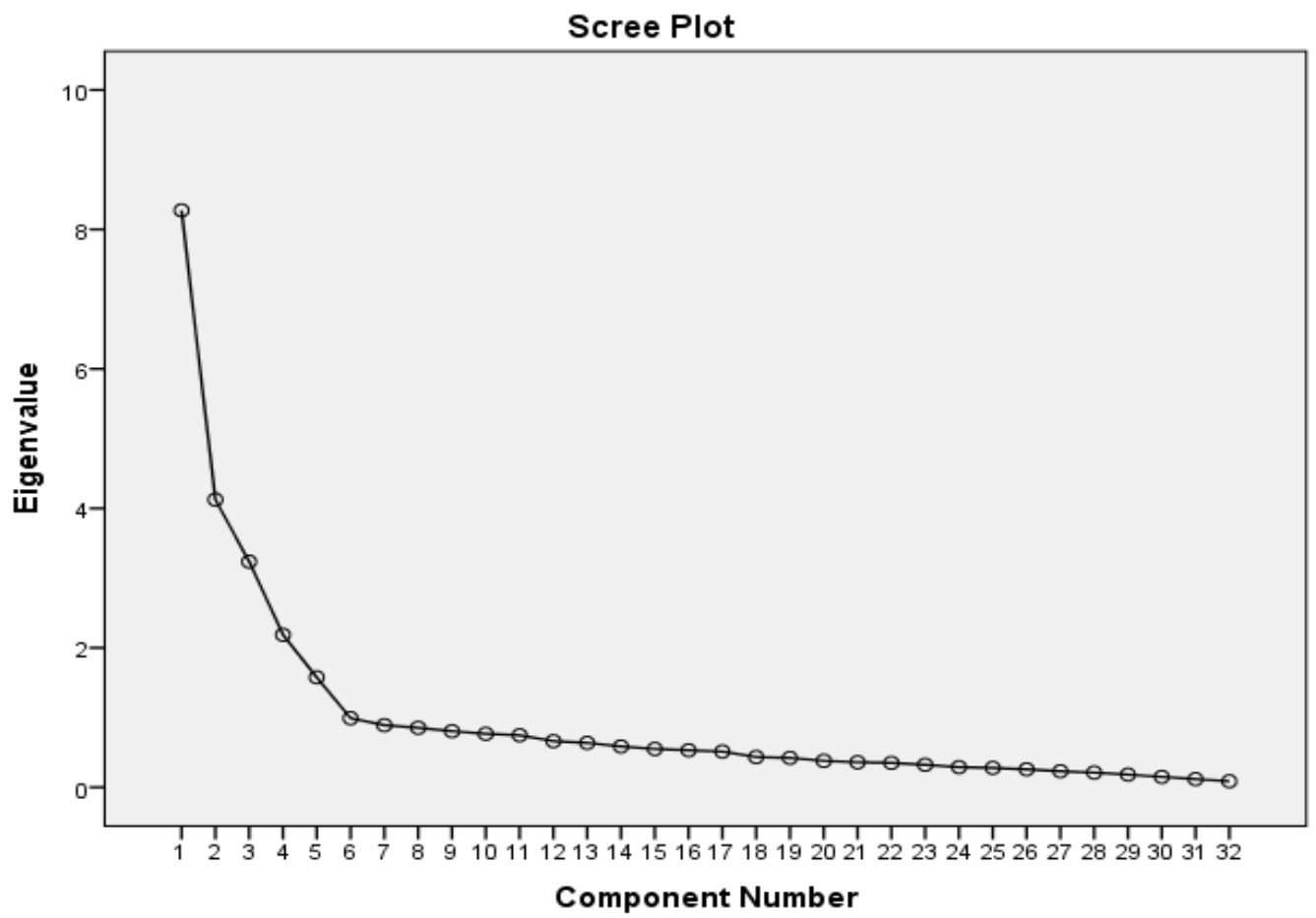

تم استخدام التحليل العاملي الاسنكثافي على (rᄉ) عبارة ونم استبعاد المفردات التي تشبعها أقل من (• ـ.) في ضوء محك كايزر من مصفوفة الارثباط حيث نم استبعاد

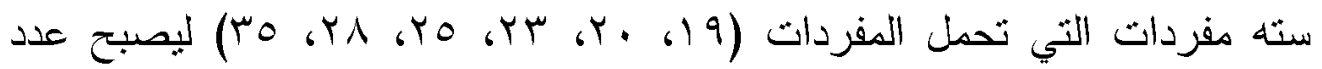
مفردات المقياس (rr) عبارة موزعة على خمسة عوامل كما هو موضح بجدول(s). 


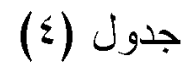

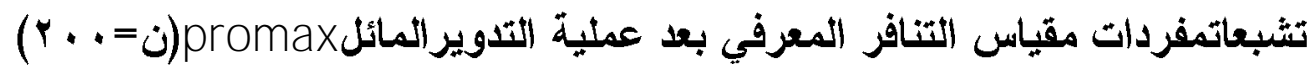

\begin{tabular}{|c|c|c|c|c|c|c|}
\hline الاثشتر اكات أو & الخامس & الرابع & الثالث & الثاني & الأول & رقبارة \\
\hline .1279 & & & & & .109 & rı \\
\hline VON & & & & & דוT. & r \\
\hline .TVE & & & & . $\{Y \wedge$ & . .0 & 10 \\
\hline r & & & & & .199 & 0 \\
\hline .VTV & & & 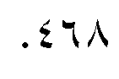 & &.$V V V$ & 9 \\
\hline .070 & & & & & $. V \leq \varepsilon$ & YI \\
\hline TH & & & & ו & TYMT & rV \\
\hline .049 & & & & & $\cdot V \cdot r$ & $r$ \\
\hline 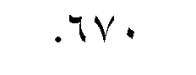 & & .014 & & & $\therefore M \Lambda$ & 1. \\
\hline .791 & .हार & & & & זדו. & YV \\
\hline & & & . & .101 & & v \\
\hline $.79 V$ & & & & .1 .9 & & $\lambda$ \\
\hline . & & & &.$V Y \varepsilon$ & & 1 \\
\hline .709 & & & & rVor & & r \\
\hline .09 & & & . $\varepsilon \cdot \varepsilon$ & $. v \leqslant 0$ & & $\mu_{1}$ \\
\hline A11 & & & & I & & rr \\
\hline .0 .1 & & & & IVI & & $1 \pi$ \\
\hline .019 & & & . 141 & & & $1 \varepsilon$ \\
\hline
\end{tabular}

العدد الرابع والأربعون


الخصائص السيكومترية لمقياس التنافر المعرفي لاى معلمي المرحلة الابتدائية

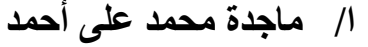

\begin{tabular}{|c|c|c|c|c|c|c|}
\hline الاثشيوع أو أوات & الخامسل & الرابع & الثالثل & الثاني & الأعامل & رقعب العبارة \\
\hline 7.7 & & & . VOV & & & 11 \\
\hline $.0 \leqslant \varepsilon$ & & &.$V \cdot \varepsilon$ & & & rq \\
\hline צro. & & & & & & $1 V$ \\
\hline .0 .1 & & & ד & & & r. \\
\hline
\end{tabular}

\begin{tabular}{|c|c|c|c|c|c|c|}
\hline الثثيوع أو أثات & الخامس العامل & الكرابع & الثامل & الثانامل & الأعامل & رقب العبارة \\
\hline$. \Sigma Y \leqslant$ & & & . TrA & & & r \\
\hline . EY & & .VYE & & & & rr \\
\hline .717 & & $.79 V$ & & & & דו \\
\hline $.01 Y$ & &.$T V Y$ & & & & Ir \\
\hline .oro & & .779 & & & & 7 \\
\hline.$\leqslant 0$. & & צחז. & & & & 11 \\
\hline$. T \leq Y$ & 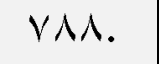 & & & & & YT \\
\hline .7 .7 & ৩५A. & & & & & 17 \\
\hline מע & VY & & & & & $\varepsilon$ \\
\hline \multirow[t]{3}{*}{.$\leqslant \leq 9$} & $T . Y$. & & & & & Y \\
\hline & $1.0 \mathrm{VV}$ & Y.IAV & צמצ.r & E.IYY & A.rVT & الجامن \\
\hline & $\Sigma .9 r V$ & ס סק.גר & $1 . .111$ & IY.А9E & Yo.Aor & نسبة \\
\hline
\end{tabular}

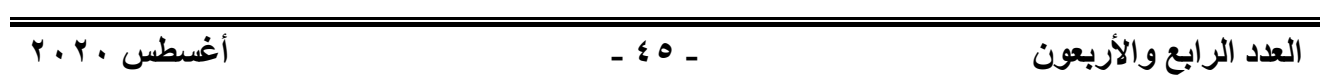




\section{ب-التحليل العاملي التوكيدي Confirmatory factor analysis}

ثم إجراء التحليل العاملي التوكيدي باستخدام برنامج Amos V22 لمقياس

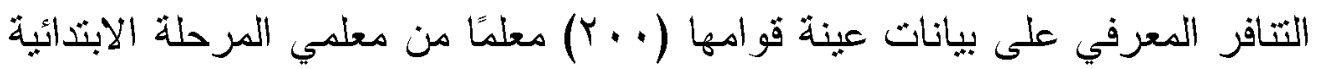
مختلفة عن العينة الاستطلاعية التي تم استخدامها في التحليل العاملي الاستكثافي. الهدف من استخدامه التحقق من مــدى مطابةــة أبعــاد مقياس التنافر المعرفي

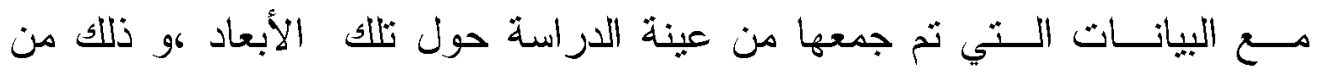
خلال دراسة العلاقــة بـين أبعــاد النتافر المعرفي والفقـرات المعـبرة عنها ومدى قدرةا لعبار ات علـى التعبــيرعـن كـل بعد.

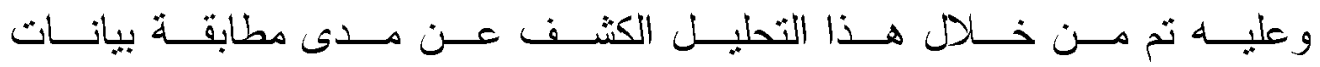
عينــة مقياس التتافر المعرفي، وثم تحديد نموذج التحليل العاملي التوكيدي من الدرجة الثانية وفى ضوء ما أسفر عنه التحليل العاملي الاستكثافي عن استخلاص (0) (0) عوامل وهى: (0) 1- العامل الأول وثم تشميته بُعد العمل وشمل على (• (1) عبار ات. r-العامل الثاني ونم ثسميته التكيف الثخصي وشمل على (V) عبار ات. ب-العامل الثالث ونم تشميته البُعد الاجنماعي وشمل على (؟) عبار ات. ـ -العامل الرابع ونم ثسمينه البُعد العاطفي وشمل على (0) عبار ات. 
0-العامل الخامس ونم تسميته النطويرو الاستمر ارية وشمل على (s) عبار ات.

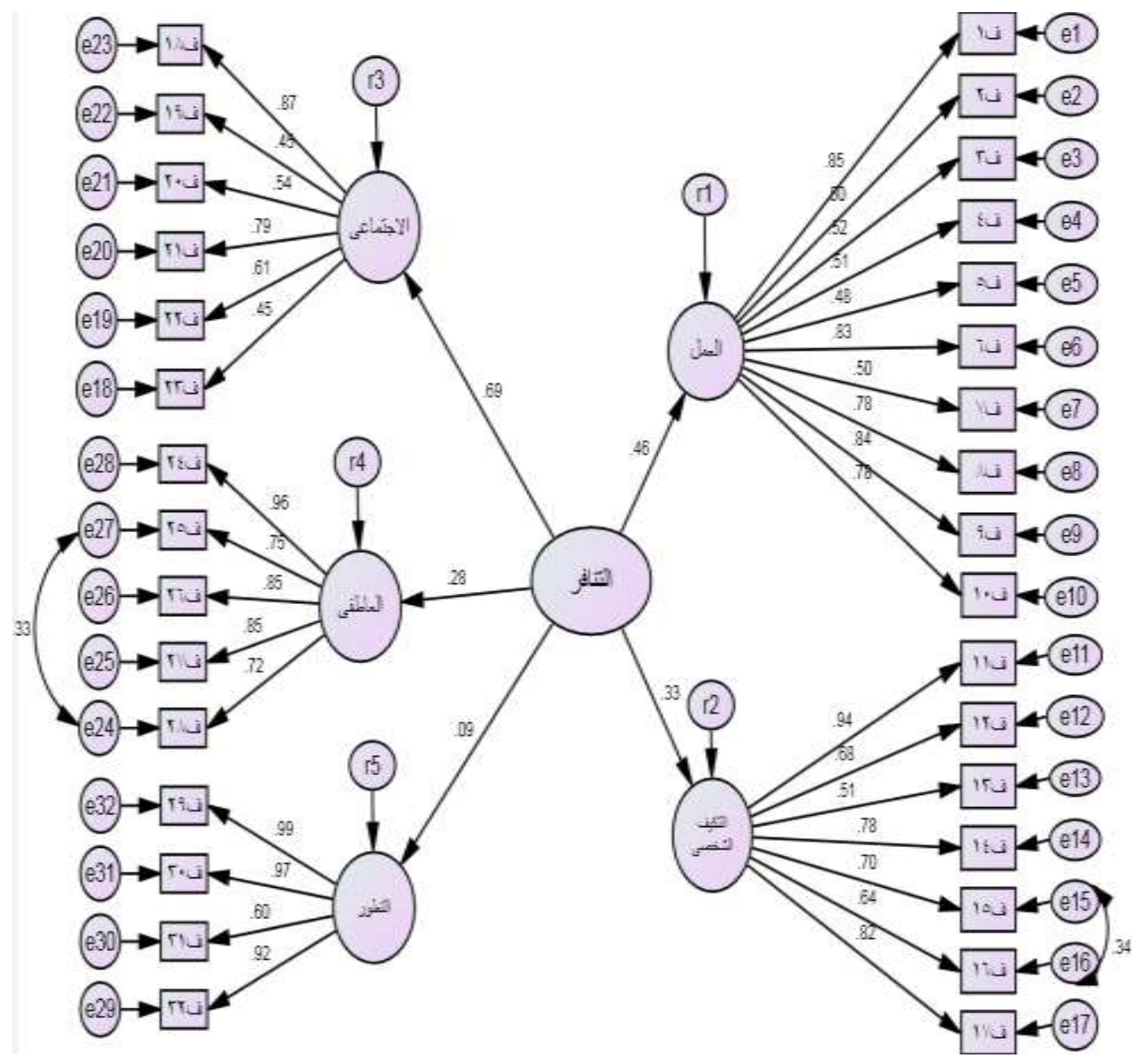

شكل (1) نموذج مقياس التنافر المعرفي

كيوضح شكل (1) أن كل معاملات التشبعات بين المفردات والمتغيرات الكامنة تجاوزت (•ع. •) حبث ثم إضافة ارثباط ان لبعض الفقرات مقترحة من البرنامج بهدف تحقيق جودة مطابقة للنموذج ويوضح جدول (0) مؤشرات المطابقة لمقياس التتافر المعرفي. 
جدول (0)

مؤشرات المطابقة لمقياس التنافر المعرفي

\begin{tabular}{|c|c|c|c|c|c|c|c|}
\hline هودئش & الحرية & $\begin{array}{l}\text { مربع كاي } \\
\text { Chi- } \\
\text { square }\end{array}$ & متوسط & تؤن مؤشر - & $\begin{array}{c}\text { المطابقة } \\
\text { المقارن } \\
\text { CFI }\end{array}$ & 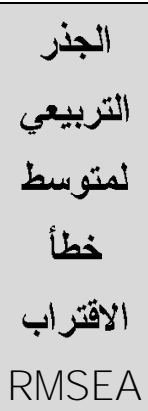 & هؤشرَات \\
\hline.$\wedge \ldots$ & $\varepsilon O V$ & 151.11 & $\ldots \leqslant V$ & $.9+1$ & .911 & צ . . & القحسوبة \\
\hline
\end{tabular}

و ويظهر جدول (9) أن مؤشرات المطابقة حققت مطابقة جيدة لمقياس التنافر المعرفي القائم على منتج التحليل العاملي الاستكثافي، حبث بلغ الجذر التربيعي لمتوسط خطأ

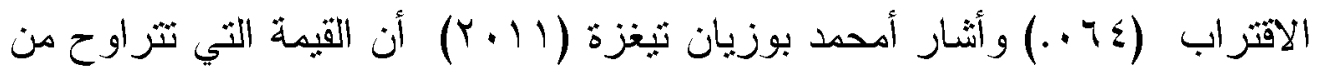
بين (0...) ، (1...) تدلى على وجود خطا ثقارب معقول، وبلغ مؤشر المطابقة

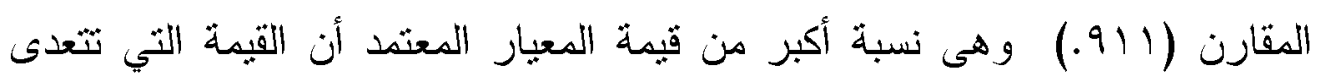

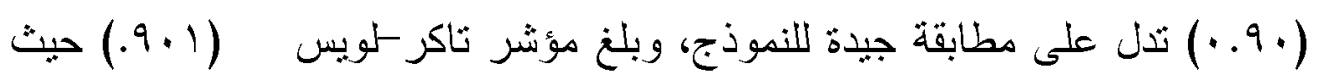

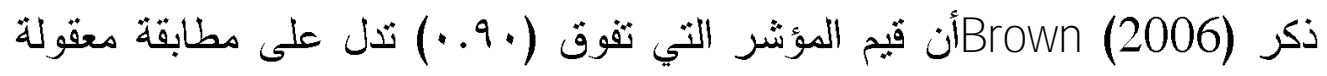

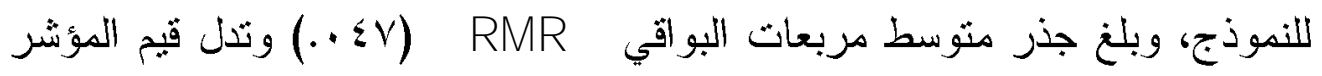
انه كلما قل انخفضت قيمته كلما دل على مطابقة جيدة، وبلغ مؤشر جودة المطابقة

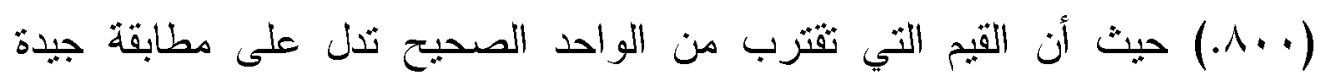

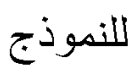

العدد الرابع والأربعون


جدول (T)

\begin{tabular}{|c|c|c|c|c|c|c|c|c|c|}
\hline مستوى & $\begin{array}{r}\text { التسرجة } \\
\text { Critical } \\
\text { ratio }\end{array}$ & $\begin{array}{r}\text { الخطأ } \\
\text { المعاري } \\
\text { standard } \\
\text { error }\end{array}$ & Estimate & المفردات & مستوى & $\begin{array}{r}\text { النسبة } \\
\text { Critical } \\
\text { ratio }\end{array}$ & $\begin{array}{r}\text { الخطأُ } \\
\text { standard } \\
\text { error }\end{array}$ & $\begin{array}{r}\text { Estimate } \\
\text { التقيرات }\end{array}$ & المفردات \\
\hline$\ldots .1$ & D.AT. & $\$ 19$. & r. $\leqslant 4 \%$ & فی| & & & & $1 \ldots$. & ف1 \\
\hline$\ldots .1$ & \& & YAQ. & $1 .+49$ & ف91 & $\ldots+1$ & V.TAT &.$v \ldots$ & $01 \leqslant$. & فن \\
\hline$\ldots$. & $\leq . \lambda \leqslant 0$ & $m$ & 1.0 .4 & ف.ץ & $\ldots .1$ & ห.१११ & $. v .$. & $0 \leqslant r$. & فت \\
\hline$\ldots .1$ & $0 . V 01$ & $\leq .1$. & Y.rV. & ف1וץ & $\ldots .1$ & v.o1. & . vi. & 9.7. & ف؛ \\
\hline \multirow[t]{2}{*}{.... } & 0.100 & 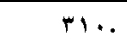 & $1.0 \times 9$ & فץY & $\ldots .1$ & $v .1 \leqslant r$ & . v.. & $0 .{ }^{\prime}$. & فن \\
\hline & & & $1 \ldots$. & فTr & $\ldots \cdot 1$ & $19 . .04$ & . . 9. & $9 \leqslant 4$ & فי \\
\hline .... & IY.TAY & $11 \leqslant$. & ד & فـץ & $\ldots .1$ & V.THT & $\cdot A$. & OAO. & فV \\
\hline$\ldots .1$ & IY.TAT & . AT. & $1 . .+4$ & فهץ & $\ldots .1$ & IT.Aor & $.7 \leqslant$. & AqT. & فג \\
\hline$\ldots .1$ & M.AQY & $.9 \leqslant$. & $1 .+10$ & فעיץ & $\ldots .1$ & 10.018 & . $7 \leqslant$. & ११.. & فه \\
\hline \multirow[t]{2}{*}{.... } & $11 . \leqslant 0 r$ & $1 \cdot \lambda$. & $1 . \leqslant 41$ & فVVץ & $\ldots .1$ & IT.TAT & $.7 \%$. & ATO. & ف.1 \\
\hline & & & $1 \ldots$. & فـץ & & & & $1 \ldots$ & ف1" \\
\hline$\ldots$. & $r 1 . . v r$ & . & $1 . .01$ & فـ9 & $\ldots .1$ & 11.4 .1 & $.7 \%$. & vri. & فז! \\
\hline$\ldots .1$ & YA.qYT &.+4. & 1.14 & ف." & $\ldots .1$ & $V . \Lambda \leqslant 0$ & .79. & $0 \leqslant Y$. & فזו \\
\hline \multirow[t]{2}{*}{$\cdots \cdot 1$} & $1 . .719$ & . $7 \leqslant$. &. $.7 V A$ & فاس & $\ldots+1$ & $1 \leq .491$ & $.0 \leqslant$. & var. & ف؛1 \\
\hline & & & $1 \ldots$. & فזץ & $\ldots+1$ & M. &.$\triangle A$. & VYV. & ف10 \\
\hline & & & & & $\ldots .1$ & 1.940 & $.7 r$. & १९५. & ف41 \\
\hline & & & & & $\ldots .1$ & $19 . .85$ & $.0 \leqslant$ & A.t. & فע| \\
\hline
\end{tabular}

ينضح من جدول(T) أن مستوى الدلالة لجميع المفردات دالة إحصائيًا عند مستوى لئرا

| (...1) وبذلك أسهمت في نكوين العوامل.

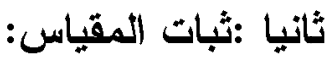

1-معامل الفاكرونباخ:

تم حساب ثبات المقياس باستخدام معادلة الفاكرونباخ كما هو موضح بالجدول (v)

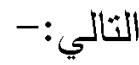

العدد الر ابع والأربعون




\section{جاول(IV)}

ثبات المقياس باستخدام معادلة الفاكرونباخ

\begin{tabular}{|c|c|c|c|}
\hline معامل الفاكرونباخ & عدد العبارات & الأبعاد & م \\
\hline .19. & 1. & بُعدالعمل & 1 \\
\hline.$\lambda r \varepsilon$ & $v$ & التكيفالشخصي & r \\
\hline (N) & 1 & البُعدالاجتماعي & r \\
\hline vo. & 0 & البُعدالعاطفي & 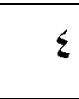 \\
\hline 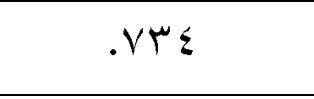 & $\varepsilon$ & التطويرو الاستمر ارية & 。 \\
\hline $.19 \leqslant$ & rr & الأبعاد & إجمال \\
\hline
\end{tabular}

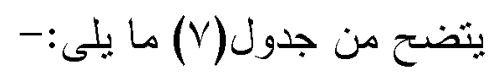

-ثراوحت قيم معاملات الفالأبعاد المقياس ما بين (عبv.-..19.) بثبات كلى (1 (1.) وهى معاملات ثبات مرتنعة مما بدل على أن المقياس على درجة مقبولة من الثبات وبذلك يمكن الوثوف به، واستخدام أداة البحث.

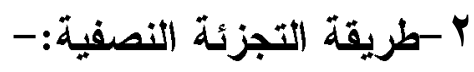
تم حساب ثبات المقياس ككل بطريقة التجزئة النصفية حيث تم تجزئة عبارات

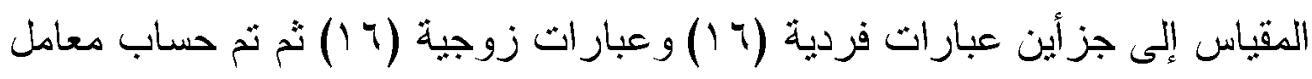

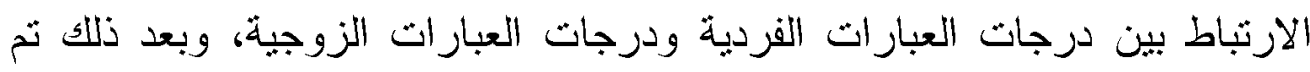

تصحيح معامل الارتباط بمعادلة Spearman- Brown وجاءت النتائج كالثالي:

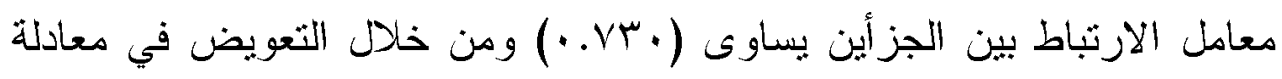

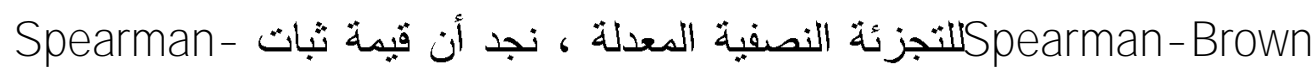

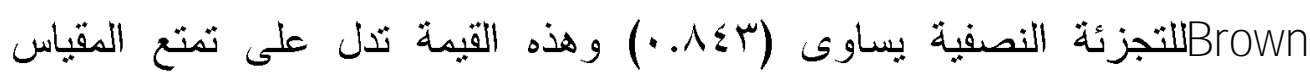

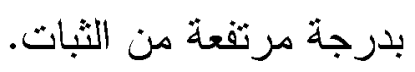

العدد الرابع والأربعون




\section{الصورة النهائية للمقياس وطريقة التصحيح}

تكون المقياس في صورثه النهائية من (بس) مفردة ملحق (1)، بـتم تصـحيح

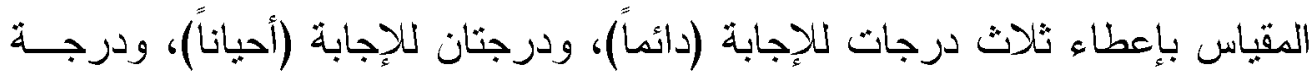

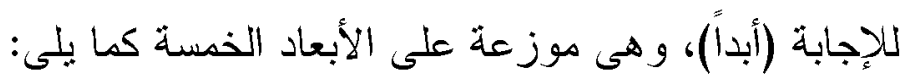
1- البُعد الأول التنافر المعرفي في العمل (بُعدالعمل) ويعبر عن حدوث حالة عـدم

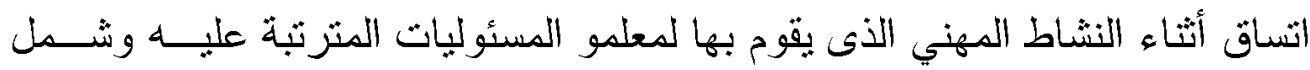

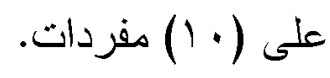

r- البُعد الثاني التنافر المعرفي في مجال التكيف الثُخصي(الثكيف الثخصي) ويعبر عن حدوث ثتاتض أثناء نكيف المعلم مع ذاته ومع الأخرين و التصرف بشكل منطقي و القدرة على التكبف مع التغييرات التي تحدث وشمل على (V) مفردات. ب-البُعد الثالث التنافر المعرفي في السياق الاجتماعي(البُعـدالاجتماعي) ويعبــرعن حدوث حالة من النتاقض أثناء تعامل المعلم مع المحيط الاجتماعي وشمل على (ب)

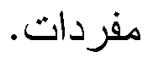

ـ-البُعد الرابع التنافر المعرفي في المجال العاطفي(البُعدالعاطفي) ويعبر عن حدوث

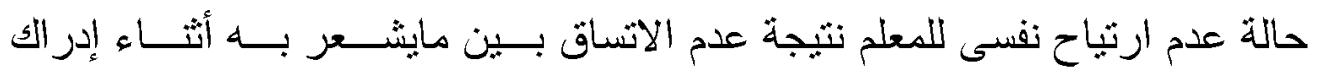

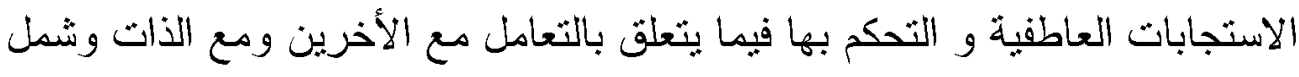

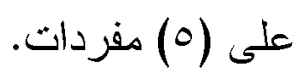

ه-البُعدالخامس التتافر المعرفي في النطوير والاستمرارية (النطويروالاســتمرارية)

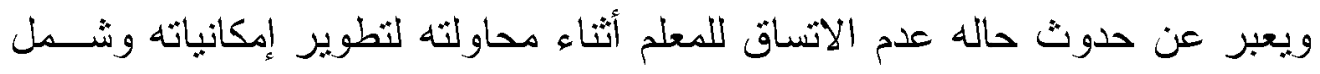
على (乏) مفردات.

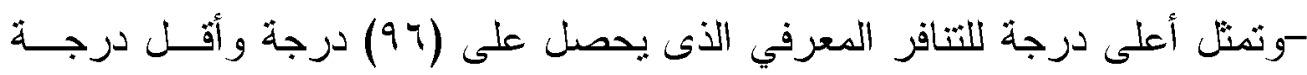
لالنتافر المعرفي تمثل (rr) درجة. 
جدول (^)

توزيعفردات المقياس على الأبعاد

\begin{tabular}{|c|c|c|c|}
\hline 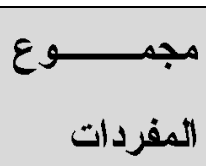 & أرقامالمفردات & البعد & r \\
\hline 1. & 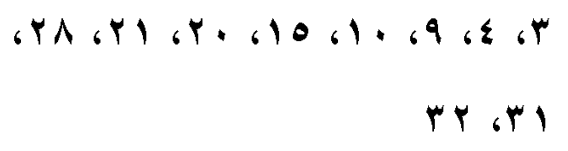 & بعد العمل & 1 \\
\hline v & YV 6 Y & التكيف الثخصي & r \\
\hline 9 & 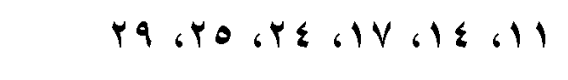 & البعد الاجتماعي & $r$ \\
\hline$\bullet$ & $r .61961161467$ & البعد التعاطفي & $\varepsilon$ \\
\hline$\varepsilon$ & Kr, & التطوير والاستمرارية & ○ \\
\hline rr & لــــــوع & 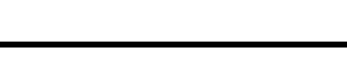 & \\
\hline
\end{tabular}

\begin{tabular}{|c|c|c|c|c|}
\hline أبدا & أحياناً & دائماً & الفقرة & م \\
\hline & & & أفضل كتمان مشاعري بداخلي بالرغم أنى أظهر ها & 1 \\
\hline & & & 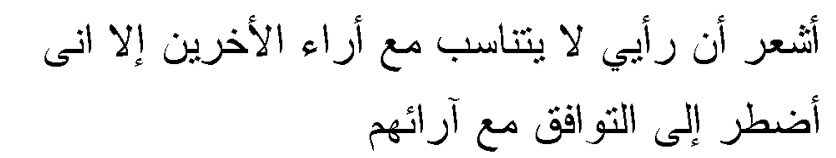 & Y \\
\hline & & & أحب عملي إلا انى أرغب في تغييره & r \\
\hline & & & وأقدر العدل والالتزام في علي المدرسي لكنى أفضل & $\varepsilon$ \\
\hline & & & 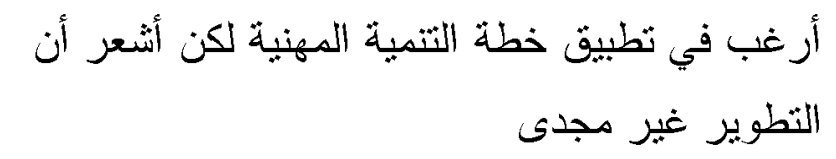 & 0 \\
\hline
\end{tabular}


الخصائص السيكومترية لمقياس التنافر المعرفي لاى معلمي المرحلة الابتدائية / / ماجدة محمد على أحمد المد

\begin{tabular}{|c|c|c|c|c|}
\hline أبدا & أحياناً & دائماً & الفقرة & b \\
\hline & & & أتوثز من ضجيج التلامبذ لكنى لا أحب الهدوء & 7 \\
\hline & & & أستفبد من تجاربي السابقة لكنى أحبط عندما أتذكرها & $v$ \\
\hline & & & أحب المكان الذى أعيش فيه رغم أنه غير مناسب لي & $\lambda$ \\
\hline & & & أفضل الحفاظ على المو اعبد لكنى أذهب إلى على & 9 \\
\hline & & & أكلق بقدر اتي إلا أنى لا أقوم بالو اجبات و المسئوليات التي & 1. \\
\hline & & & لالوحدة أصدقاء كثر لكن بنتابني الثعور بالخوف من & 11 \\
\hline & & & أعنرف بخطئي إذا أخطأت بالرغم من شعوري بالتونز & Ir \\
\hline & & & وأرغب في الحديث مع الأخرين رغم حبي للوحدة & ir \\
\hline & & & أحب حياتي التي أعيشها لكن أرغب في تغيرها & $1 \leqslant$ \\
\hline & & & بالستطيع أن أنجح بعملي المدرسي إلا أنه بنتابني شعور & 10 \\
\hline & & & أطلع على كل ما هو جديد في عملي لكن أثنعر أن & 17 \\
\hline & & & أصنع صداقات جديدة لكن لاأهتم بالعلاقات الاجنماعية & iv \\
\hline & & & 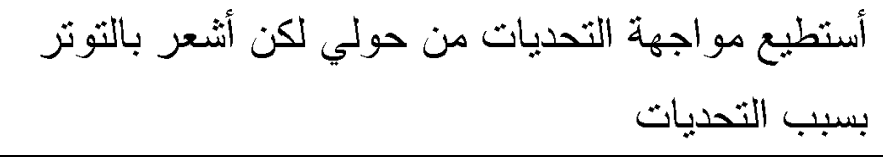 & 11 \\
\hline & & & تضايقني التفاؤل و المرح لكنى أتثـاءم من أبي مو اقف & 19 \\
\hline
\end{tabular}


الخصائص السيكومترية لمقياس التنافر المعرفي لدى معلمي المرحلة الابتدائية

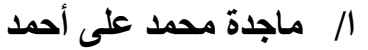

\begin{tabular}{|c|c|c|c|c|}
\hline 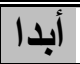 & أحياناً & دائماً & الأفزرة & s \\
\hline & & & ألىحل الثي مسئولية أكلف بها في المدرسة رغم أنى أفثمر & $r \cdot$ \\
\hline & & & 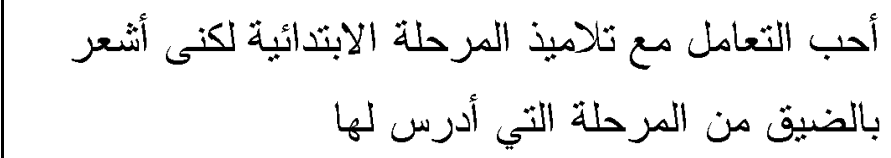 & $Y_{1}$ \\
\hline & & & أخطط دائما لمستقبلي لكنى أشتعر بالخوف تجاه المستقبل & rt \\
\hline & & & 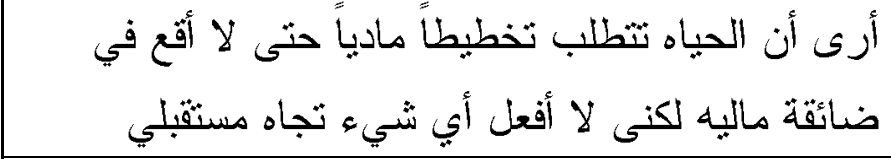 & r \\
\hline & & & أصدقائي يروني شخص كفء لكنى أرث نفسى أنى غير كفء & rs \\
\hline & & & أحب المجتمع الذى أعيش فيه لكن أرغب في ثركه & Yo \\
\hline & & & 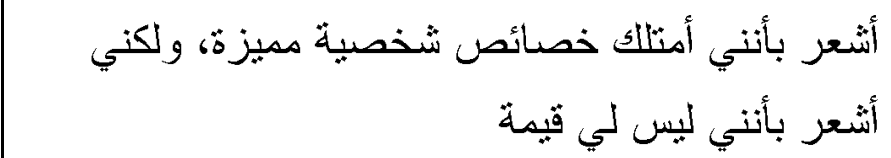 & ry \\
\hline & & & أطبق الروثين البومي رغم أني أسناء من ذلك الروثين & rV \\
\hline & & & أحب النجاح في عملي المدرسي إلا إني لا أسعى إليه & rᄉ \\
\hline & & & أنبادل الأفكار مع زملائي بالرغم من أنى لا أحب أحد & rq \\
\hline & & & وأنشعر بالرضا النفسي لكن أحزن بسبب بعض أفكاري & r. \\
\hline & & & أحب حضور التدريبات لكنى أشعر بالملال منها & щ \\
\hline & & & طول فترة العمل لفترات طويله رغم أنى أشعر بالضيق من & rt \\
\hline
\end{tabular}




\section{المراجع}

أمحد بوزيان تيغرة (11 + ب).التحلبل العاملي الاستكشافي والتوكببي ـ دار المسيرة

$$
\text { للنشّر و الثوزيع. }
$$

رنا رفعت شوكت (T ( • Y). التتافر المعرفي لدى طلبة كلية التربية الأساسية الجامعة

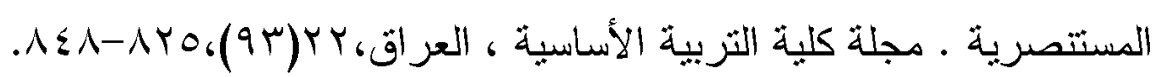
عمر عطاله على (Y V . V). التتافر المعرفي وعلاقته بأساليب التفكير ومصادر الدعم الاجثماعي لدى طلاب جامعه اليرموك. رسالة دكتوراه، جامعه البرموك،

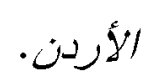

يوسف قطامي (11 ( ب). نظرية التتافر والعجز والتغبير الدعرفي. دار المسيرة

$$
\text { للنشر و التوزيع. - مبع }
$$

Brehm, J. (2007). A brief history of dissonance theory. Social and Personality Psychology Compass, 1(1), 381-391.

Brown, T. (2006). Confirmatory factor analysis for applied research. New York.:The guilford press.

Burns, C. (2006). Cognitive dissonance theory and the induced-compliance paradigm: concerns for teaching religious studies. Teaching Theology \& Religion, 9(1), 3-8.

Festinger, L. (1957). A theory of cognitive dissonance.Stanford California: Stanford University Press.

Harmon-Jones, E., \& Harmon-Jones, C. (2007).Cognitive dissonance theory after 50 years of development.Zeitschrift fur Sozialpsychologie, 38(1), 7-16. 
Kaaronen, R. (2018). A Theory of predictive dissonance: Predictive processing presents a new take on cognitive dissonance. Frontiers in Psychology, 9,1-15.

Mckimmie, B. (2015). Cognitive Dissonance in Groups.Social and Personality Psychology Compass, 9(4), 202-212

Richter, T., \& Ferraro, R. (2015). Cognitive dissonance reduction in relation to grade point average, but not to intelligence.StudiaPsychologica, 57(2), 115-119. 